\title{
Aplicações do Urânio em datação
}

\author{
$J \bigcirc \bar{A} \bigcirc \mathrm{M}$. P EIX $\mathrm{X} O \mathrm{~T} O \mathrm{CABRAL}$
}

$\mathrm{E}$ M 1896, BECQUEREL DESCOBRIU QUE os sais de urânio emitem espontaneamente radiações. No ano seguinte, Marie Sklodowska Curie pôs em evidência o mesmo fenómeno em sais de tório e, passado pouco tempo, de colaboração com Pierre Curie, descobriu o polónio e o rádio. Em 1899, Rutherford verificou que tais radiações são compostas pelo menos por dois tipos distintos, $\alpha$ e $\beta$. Além disso, ao realizar uma série de experiências com o tório, descobriu a "emanação" cuja natureza determinou mais tarde, juntamente com Soddy, identificando-a com um gás inerte - o torão $\left({ }^{220} \mathrm{Rn}\right)$. Esta descoberta acabou por resultar muitíssimo frutuosa, de tal modo que em 1903 Rutherford e Soddy conseguiram já traçar um esboço razoável das séries radioactivas do urânio e do tório. Entretanto, ambos os investigadores tinham reconhecido que as particulas $\alpha$ são átomos de hélio completamente ionizados, que há hélio em minérios de urânio e tório e que o decaimento radioactivo ocorre de acordo com uma lei exponencial.

\section{Métodos do U/He e do U/Pb}

Em 1905, Rutherford propôs um método para determinar a idade da Terra a partir da quantidade de hélio acumulada em minerais de urânio. Com base em resultados obtidos por discipulos seus, na análise duma amostra de fergusonite, chegou mesmo a anunciar uma idade de 40 milhões de anos (m.a.).

Por outro lado, ainda em 1905, Rutherford, tendo em conta a conclusāo de Boltwood de que o chumbo era o produto final das referidas séries, propôs um novo método de datação baseado na quantidade de chumbo presente naqueles minerais. Servindo-se desta ideia, Boltwood analisou 26 minerais de urânio diferentes e conseguiu resul- tados compreendidos entre 26 e 570 m.a.

Tanto o primeiro valor como os obtidos a seguir estavam errados, o primeiro devido sobretudo ao facto de o hélio não ser completamente retido pela maior parte dos minerais uraníferos e os outros em virtude de Boltwood só tomar em consideração a série do ${ }^{238} \cup$, de o periodo do rádio ainda não ter sido medido de modo correcto e de não se saber que a desintegração do tório conduzia igualmente à produção de chumbo. Apesar disso, os valores determinados por Boltwood não deixaram de ser importantes pois mostraram que a Terra era muito mais velha do que os cálculos de Lord Kelvin no último quartel do séc. XIX baseados em considerações de natureza termodinâmica - faziam crer (20-40 m.a.).

\section{Método do U,Th/Pb}

Foi só em 1913 que se descobriu que o chumbo provinha também da desintegração do tório e se começou a considerar tal facto no método de datação. Mas foi sobretudo ao uso do espectrómetro de massa, desenvolvido por Aston e Dempster, que ficaram a dever-se os maiores progressos que vieram a fazer-se posteriormente.

Em 1931, Holmes, que se tornara o maior especialista em datação, concluiu com base em novas determinações que a idade da Terra "excedia 1460 m.a., não era provavelmente inferior a 1600 m.a. e era provavelmente muito menor que 3000 m.a.". Mas o erro cometido, embora mais pequeno do que antes, continuava a ser enorme devido sobretudo ao desconhecimento das quantidades de chumbo não radiogénico que poderiam estar presentes nos minerais de urânio e tório.
A primeira grande contribuição para o esclarecimento deste problema foi dada por Nier, no final dos anos 30, ao observar que as proporções de ${ }^{206} \mathrm{~Pb},{ }^{207} \mathrm{~Pb} \mathrm{e}$ ${ }^{208} \mathrm{~Pb}$ (isótopos radiogénicos) em minerais de chumbo não radioactivos, relativamente $\mathrm{ao}^{204} \mathrm{~Pb}$ (não radiogénico), são tanto menores quanto maior a idade dos minerais. Baseando-se nestes resultados e em certas hipóteses, vários autores procuraram determinar de novo a idade da Terra obtendo valores compreendidos entre 2900 e 3500 m.a.

A segunda grande contribuição deve-se a Patterson, nos anos 50, e a Ostic e Tilton, nos anos 60, ao medirem as composições isotópicas do chumbo em diversos meteoritos. Deste modo, combinando os resultados obtidos nas medições com dados relativos a rochas terrestres e atendendo a certas teorias sobre a evolução das razões isotópicas do chumbo, alguns investigadores chegaram a um valor para a idade da Terra de c. 4500 m.a.. Este é o valor ainda hoje aceite.

\section{Método do ${ }^{234} \mathrm{U} /{ }^{230} \mathrm{Th}$}

O urânio aplica-se também na datação de artefactos arqueológicos. Aqui, o método mais corrente tem sido o do ${ }^{234} \mathrm{U} /{ }^{230} \mathrm{Th}$ usado para datar materiais calcários designadamente estalagmites, travertinos, corais, etc..

Este método fundamenta-se no facto de a água conter normalmente urânio mas não tório. Assim, quando o carbonato dissolvido nas águas precipita, os cristais de calcite produzidos retêm urânio. Nos cristais, começa então a acumular-se ${ }^{230} \mathrm{Th}$ em resultado da desintegração do ${ }^{234} \mathrm{U}$ retido, ou seja, a razão entre as quantidades de ${ }^{230} \mathrm{Th}$ e ${ }^{234} \mathrm{U}$ passa a aumentar com o tempo, de acordo com as leis do decaimento e do crescimento radioactivos, até se atingir o equilibrio 
entre os dois radionuclidos o que acontece ao fim de c. 500 mil anos (k.a.). A medição daquela razão na calcite permite, portanto, determinar a data da sua formação. Fazendo uso da espectrome- tria de massa, os limites de aplicação do método são 1 k.a. - 500 k.a..

Ultimamente, o método do ${ }^{234} \mathrm{U} /{ }^{230} \mathrm{Th}$ tem sido também usado na construção da curva de calibração de datas de ${ }^{14} \mathrm{C}$ desde o limite permitido pela dendrocronologia (11,9 k.a. BP) até c. 40 k.a. BP. Para isso, tem-se recorrido a corais com idades maiores que o referido limite, aos quais se aplicam ambos os métodos de datação.

\section{O Urânio na Mundovisão Científica}

\section{Introdução}

Embora reconhecendo toda a importância científica da descoberta dos raios $X$ (em Novembro de 1986, por Wilhelm Conrad Roentgen) talvez não se exagere dizendo que a sua consequência mais importante foi, ainda que inviamente, a descoberta (em Fevereiro de 1896, por Henri Becquerel) da radioactividade. E tudo se deveu à maneira como Roentgen cuidou da sua glória enviando para cientistas estrategicamente colocados na Europa notícias do seu trabalho com imagens obtidas com a "nova espécie de raios". Assim, na Academia das Ciências de Paris, Poincaré apresenta o trabalho. $\mathrm{O}$ que aconteceu depois continua em muitas narrações mal contado Parece, com efeito, que não foi uma sugestão de Poincaré mas de um dos assistentes, Becquerel, que relacionou a fluorescência no tubo de Crookes emissor dos novos raios com a produção destes. De todas as formas, o elemento de serendipity na descoberta tem sido exagerado ainda que a selecção de sais de urânio se devesse à casualidade do interesse de gerações da família Becquerel pois que já o avô de Henri tinha mostrado que a fluorescência dos sais de urânio era intensa em sais urânicos e nula em sais uranosos, o que virá a ter uma importância óbvia na descoberta. Verdadeiramente, a serendipity intervem no episódio final quando o sal duplo de urânio e potássio foi colocado sobre uma lâmina de cobre em forma de cruz de Malta, com a espessura de dois milímetros, sobreposta a uma chapa fotográfica protegida da luz por um papel espesso, ficou dentro de um gaveta dias seguidos, por falta de Sol para excitar a fluorescência e, mesmo assim, Becquerel ter revelado a chapa. Desta forma, o urânio fica ligado não por si mesmo mas, como se veria depois, pela sua descendência, à descoberta da radioactividade, nome dado ao fenómeno por Marie Curie, anos depois. Como é óbvio, não foram as radiações do urânio as responsáveis pela exposição da película. Com efeito, os raios que emitia o urânio não ultrapassavam mais do que 0,004 milimetros de alumínio. É difícil dizer quem verdadeiramente descobriu a radioactividade do urânio (melhor, dos urânios) ainda que o meu candidato seja Ernest Rurherford, em 1898, com as suas experiências sobre a absorção das radiações do urânio em lâminas de alumínio, onde se revelou a presença de raios a que chamou raios alfa. A Becquerel se devem estudos iniciais que iriam balizar o caminho de muitas descobertas futuras. Já com um electroscó- pio, e não com chapas fotográficas mostra que a temperatura ( $\mathrm{de}-180^{\circ} \mathrm{C}$ a $80^{\circ} \mathrm{C}$ ) não influi na radioactividade da amostra do sal de urânio (mais um dos muitos casos em que a insensibilidade dos instrumentos facilitou o progresso inicial do estudo científico). Seguindo essa radioactividade durante quatro anos conclui pela persistência do fenómeno com a mesma intensidade (outro caso de insensibilidade favorável). É aqui que se questiona o "princípio da conservação da energia", que é imprudente ignorar como muitos físicos aprenderam duramente à sua custa. Seguem-se os estudos da proveniência da energia que "alimentava a radioactividade" ( Da luz? Do ar? Do vácuo?) que mostra que a fantasia não é apenas privilégio dos criadores literários a quem infelizmente (ou talvez não), falta a "polícia" da experiência para os encaminhar para a "verdade", a que se chama científica. Esquece-se muitas vezes que se deve a Becquerel, principalmente, o reconhecimento de que os raios catódicos eram electrões (descobertos oficialmente por J. J. Thomson em 1898), e que os electrões eram uma das partículas emitidas por alguns elementos radioactivos (os raios beta de Rutherford). Os raios gama, os responsáveis verdadeiros pela descoberta da radioactivida- 